\title{
Comparison of personality between juveniles and adults in clonal gecko species
}

\author{
Osamu Sakai ${ }^{1}$ (i)
}

Received: 1 December 2017 / Accepted: 27 May 2018 / Published online: 8 June 2018

(c) Japan Ethological Society and Springer Japan KK, part of Springer Nature 2018

\begin{abstract}
The developmental perspectives of animal personality enhance our understanding of how personality structure changes in relation to life stage. Clonal animals are ideal models for developmental studies because personality differences can be solely attributed to environmental factors. Here, I investigated the presence of personality within a species of clonal gecko, Lepidodactylus lugubris, at different developmental stages. For juveniles and adult geckos, I measured exploration (reaction to a novel situation) and boldness (risk-prone tendency) and evaluated repeatability and correlation of these behavioural traits. Each gecko exhibited different exploration and boldness with significant repeatability through time but no correlation between these behavioural traits. Small juveniles were composed of only bold and low explorative individuals but large juveniles and adults were composed of various personality type individuals. These results demonstrate that subject geckos have a similar personality structure across life stages and that exploration and boldness are independent personality without forming behavioural syndrome structure. Biased composition of personality type between life stages suggests that appearance of different personality type individuals during an early ontogenetic stage generates personality variation within the clonal population. This study provides developmental insight about personality structure and its composition in clonal animals living in the wild.
\end{abstract}

Keywords Animal personality $\cdot$ Developmental stage $\cdot$ Clonal animal $\cdot$ Parthenogenetic gecko $\cdot$ Lepidodactylus lugubris

\section{Introduction}

Consistent behavioural differences between individuals are described as animal personality, and this topic is a burgeoning field of study in behavioural ecology and ethology (Gosling 2001; Réale et al. 2007; Carere and Maestripieri 2013). Animal personality is reflected by consistency of a single behavioural trait through time (repeatability) and across situations, and by correlations between multiple behavioural traits in different contexts (behavioural syndromes) (Sih et al. 2004; Bell et al. 2009). Several studies have reported that animals in a wide range of taxa have personality, demonstrating its ubiquitous nature in animals (Smith and Blumstein 2008; Bell et al. 2009; Garamszegi et al. 2012).

Osamu Sakai

osamu-lac@ethol.zool.kyoto-u.ac.jp

1 Department of Zoology, Graduate School of Science, Kyoto University, Kitashirakawa Oiwake, Sakyo, Kyoto 606-8502, Japan
The ontogeny of animal personality may enhance our understanding of its function and evolution because adaptive behavioural responses might change with different demands and selective pressures at different life stages (Stamps and Groothuis 2010; Groothuis and Trillmich 2011). In recent years, researchers have demonstrated that several animal species have personality structure that may change across life stages (Petelle et al. 2013; Guenther et al. 2014; Class and Brommer 2015; Wuerz and Krüger 2015) and that personality type is not always stable throughout an individual's life span (Müller and Müller 2015; Favati et al. 2016; Wexler et al. 2016). These findings suggest that animal personality changes across life stages that are associated with lifehistory dependent behavioural strategies.

An ideal approach to clarify the developmental mechanisms of personality is to use "replicate individuals" which are genetically identical to one another (Stamps and Groothuis 2010). In practice, clonal animals are suitable subjects as the replicate individuals because of their genetic uniformity (Vrijenhoek 1994; Schuett et al. 2011). If individuals with the same genotypes are used for developmental 
studies, we no longer have to consider the differences of genetic factors among individuals and so can attribute differences among individuals solely to environmental factors (Lewejohann et al. 2011; Freund et al. 2013). Therefore, using clonal animals is a simple and powerful approach to investigate the ontogeny of personality, but there are few studies that have dealt with the development of personality in clonal animals.

In reptiles, approximately 40 species exhibit parthenogenesis (Kearney et al. 2009). They reproduce full clonal individuals without copulation and fertilization, and exclusively female populations exist in the wild. The mourning gecko, Lepidodactylus lugubris, is an obligate parthenogenetic reptile species that shows a wide distributional range throughout tropical and subtropical areas in the Pacific, Asia, and South America (Moritz et al. 1993; Ineich 1999). Although this species includes various diploid and triploid clonal lineages with different genetic components (Ineich 1988; Ineich and Ota 1992; Radtkey et al. 1995), genetic uniformity is evident within a single clonal lineage (Yamashiro et al. 2000; Wilmhoff et al. 2003). Mourning geckos are solitary throughout their lifetime, and mothers display no parental care, which minimizes the influence of maternal effects through the interaction between mothers and juveniles. Thus, given its genetic uniformity and solitary life history, L. lugubris is an ideal subject for personality studies from a developmental perspective.

Here, I investigated the presence of personality in clonal mourning geckos, L. lugubris, at different developmental stages. Using juvenile and adult wild-caught geckos, I conducted behavioural tests repeatedly and measured exploration and boldness to assess behavioural repeatability (consistent behavioural tendencies through time) and behavioural syndrome structure (correlation between exploration and boldness). I then compared absolute values of exploration and boldness between juveniles and adults by considering several morphological and body condition factors. This allowed me to assess the effect of developmental stage and individual body condition on their behavioural trait.

\section{Materials and methods}

\section{Subjects}

The mourning geckos were collected from a small beachfront forest located in Okinawa-jima Island, Japan (26 $44^{\prime} 53.6^{\prime \prime} \mathrm{N}$, $\left.128^{\circ} 10^{\prime} 46.7^{\prime \prime} \mathrm{E}\right)$. Populations in this area were introduced in the latter half of the twentieth century and so are assumed to be recently founded populations (Ota et al. 2004). Although this species includes several clonal lineages, only a single clonal lineage (C-type clone) is distributed in the study area (Yamashiro et al. 2000). Each clonal lineage of the species can be distinguished by their dorsal dot patterns (Ineich 1988; Ineich and Ota 1992). In addition, molecular analyses supported genetic uniformity within C-type clones and validity of classification based on the dorsal dot pattern (Yamashiro et al. 2000; Wilmhoff et al. 2003; Murakami et al. 2015). Only individuals with the dorsal dot pattern unique to C-type clones were used in this experiment.

A total of four capture surveys were carried out (September 2013, June 2014, September 2014, and September 2015). Each capture period lasted for approximately 20 days. Mourning geckos are nocturnal and so on each day, I started to capture geckos at sunset and continued until midnight. Geckos were captured by hand and placed in small Ziploc bags $(10 \times 7 \mathrm{~cm})$ which had been punctured with several small holes to allow air exchange. Captured geckos were immediately transported to an indoor field-laboratory close $(<1 \mathrm{~km})$ to the beachfront forest from where they were taken. The day following capture, I measured snout to vent length (SVL), body mass, tail condition (whether tail was original or regenerated), and gravid condition (the presence of visible eggs observed through abdomen) of geckos. Except during the measurement process and behavioural tests, geckos were kept in the Ziploc bags and placed in the room of the laboratory with natural light. I did not provide food or water for geckos during the 4 days they were captive. After the experiment, geckos were marked by toeclipping to identify individuals, and released immediately in the vicinity of where they were found. This individual marking was aimed not only at the present study but was also for other studies investigating the population ecology of the focal geckos.

\section{Determination of developmental stage}

Maturation size of the mourning geckos was defined based on SVL of gravid females captured from the focal population. Out of 301 individuals collected from this field site over 3 years, the minimum SVL of a gravid female was $36.8 \mathrm{~mm}$ (Sakai 2016). Therefore, an SVL of $36.8 \mathrm{~mm}$ was set as a borderline between juveniles and sexually mature adults, which is close to values reported in other populations of this species (35.0 mm; Ota 1994). I collected and tested juveniles only in the autumn, because juvenile sized geckos were absent in the focal population in early summer (Sakai 2016).

It should be noted that several age class individuals were included in each developmental stage of the present study. Hatchlings of the C-type clones of mourning geckos are $18.0 \pm 1.1 \mathrm{~mm}$ in SVL (mean $\pm \mathrm{SD}, N=97$ ) and it takes approximately 10 months for individuals to reach sexual maturity in the wild and in laboratory populations (Sakai, unpublished data). In addition, the life span of mourning geckos is at least 3 years and sometimes over 5 years in 
captivity (Sakai, unpublished data). Thus, in the present study, the juvenile stage has age range of several months and the adult stage has an age range of several years.

\section{Behavioural tests}

First, I aimed to examine a key feature of personality (behavioural repeatability) (Réale et al. 2007; Carere and Maestripieri 2013). Second, I was also interested in whether there was a correlation between different kinds of behavioural trait (behavioural syndrome) (Sih et al. 2004). To achieve the above aims, the experiment was designed to conduct the same behavioural tests 3 times, each including two separate assays for exploration and boldness. I conducted one behavioural test on three consecutive nights, with the first test starting the night following capture. Over the four survey periods, I sometimes recaptured individuals that had been previously used for the behavioural tests. In these cases, I took these individuals back to the laboratory and repeated the same three tests as I conducted when they were originally captured. I refer to these as retests, and this allowed me to evaluate test-retest repeatability of the behavioural traits.

All experiments were conducted in the laboratory at night in darkness because the mourning gecko is nocturnal. Air temperature in the room was controlled at $27.9 \pm 1.2{ }^{\circ} \mathrm{C}$ (mean $\pm \mathrm{SD}, N=909$ recordings) for all tests. I recorded the behaviour of the geckos using a Sony digital video camera (HDR-XR550V) set to night vision mode. The experimental arena was a plastic container $(12 \times 20 \times 12 \mathrm{~cm})$, in which grid lines $(4 \times 4 \mathrm{~cm})$ had been drawn on the walls and floor. A refuge made of cardboard $(5 \times 5 \times 1.5 \mathrm{~cm})$ was set at the centre of the arena's floor. I cleaned the inside of each container with wet tissue paper after I used it for each trial. After each trial had ended, the subject was placed back into the Ziploc bag where they were being kept.

\section{Novel environment assay for exploration}

Subjects were acclimated in the Ziploc bags in the dark experimental room for at least $30 \mathrm{~min}$ before tests. After acclimation, I turned on the light and gently introduced a gecko from the bag into the experimental arena without touching it with my hands (in order to minimize a threat stimulus assumed to be a predatory attack). I immediately turned the light off again and left the room and I recorded the gecko's behaviour for the next $40 \mathrm{~min}$ with the video camera.

Exploration is defined as the reaction to a novel environment or situation (Réale et al. 2007; Carter et al. 2013). The experimental arena was a potentially novel environment for wild geckos; therefore, in this assay the number of blocks that the gecko moved into was counted as the indicator. Because geckos sometimes hid within a refuge or walked on the lid of the container which had no grid lines drawn on it, a relative exploration score was calculated by the following two steps. First, I calculated the total exploration duration when geckos were out of the refuge and the lid. Second, I divided the number of blocks in the arena that the gecko had moved by the total exploration duration (min). According to this calculation, the relative exploration tendency per minute of each subject with a different exploring duration could be evaluated, and a higher score was associated with being more explorative.

\section{Threat stimulus assay for boldness}

Immediately after the novel environment assay, I entered the experimental room and turned the light on. I proceeded to chase the gecko around the arena by hand to induce it hide into the refuge. Although chase time depended on how quickly the subject entered into the refuge (e.g., it took at least $10 \mathrm{~s}$ and at most $60 \mathrm{~s}$ ), I standardized the situation that geckos voluntarily run away into the refuge. I immediately turned the light off and left the room and I recorded the gecko's behaviour for a further $20 \mathrm{~min}$.

Boldness is defined as an individual's risk avoidance tendency (Wilson et al. 1994; Réale et al. 2007). The chase stimulus was a threat experience which the gecko would perceive as being similar to a predatory attack. Therefore, in this assay, hiding duration within the refuge was used as the indicator. The less time that has elapsed since being attacked would be associated with a higher probability that the predator is still present near the refuge when the subject re-emerges. Therefore, individuals that hid for shorter durations before re-emerging from the refuge were considered to be bolder than those which took longer to re-emerge.

\section{Data analysis}

A total of 44 juvenile (SVL; mean $\pm \mathrm{SD}=24.1 \pm 3.4 \mathrm{~mm}$ ) and 41 adult $(43.1 \pm 2.7 \mathrm{~mm})$ geckos were used for the behavioural tests. First, I investigated the effect of developmental stage on behavioural traits, so I analysed boldness and exploration for all individuals with univariate linear mixed-effect models (LMMs) (Dingemanse and Dochtermann 2013). Developmental stage (juvenile or adult) was set as a fixed factor, and individual identity and year (2013, 2014, and 2015) were fitted as random factors. Second, I examined the effect of individual body condition on behavioural traits for each developmental stage separately. In LMMs, the night of test (1st, 2nd, and 3rd night), body length (SVL mm), and tail condition (original or regenerated tail) were set as fixed factors. For the adult stage, I also added gravid condition (egg presence or absence) as a fixed factor. Individual identity and year (2013, 2014, and 2015) were fitted as random factors for all models. In addition for the adult stage, considering that behavioural tests 
were conducted at two seasons, I also added month (June or September) as a random factor. The R package "ImerTest" was used for these analyses (Kuznetsova et al. 2015), and a restricted most likelihood $t$-test using Satterthwaite approximations for degrees of freedom was used to determine the significance of fixed factors (see details in Kuznetsova et al. 2015). Behavioural repeatability through three tests was calculated by the ratio of the variance associated with the individual identity to the total phenotypic variance (i.e. sum of individual, yearly and residual variances) based on the above LMMs for juvenile and adult stages separately (Dingemanse and Dochtermann 2013). This repeatability score ranges from 0 to 1 , and a higher score indicates higher consistency within individuals compared to total phenotypic variation. A log-likelihood ratio test was used to determine the significance of random factors between models with and without a given random effect.

Test-retest repeatability was evaluated by the correlation of mean behavioural value of the three tests between the original test and the retest using Spearman's rank correlation coefficient. Time intervals between the original and the retest of the same individual should be taken into consideration for repeatability: a relatively long time scale in the context of the subject's life span potentially lowers the consistency of behavioural tendency (Bell et al. 2009). In the present study, the time intervals between two tests varied from short to long periods (mean $\pm \mathrm{SD}=103.7 \pm 154.4$ days, range $4-476$ days, $N=27$ ), so only 16 retests ( 12 adults and 4 juveniles) with short intervals (mean $\pm \mathrm{SD}=9.1 \pm 3.2$ days, range 4-17 days) were used for the analysis. This time scale is short relative to the life history of mourning geckos so we can exclude consideration of their personality change being associated with ontogeny.

I evaluated whether there was a behavioural syndrome between exploration and boldness. The mean value of the three tests was calculated in these behavioural traits, and Spearman's rank correlation coefficient was used for the analysis. All statistical calculations were conducted using the software package R ver. 3.0.2 (R Core Team 2013).

\section{Ethical note}

No death, shed tails, or sickness were recorded as a result of the experimental manipulations. Toe clipping is a method that is often used to mark individuals in herpetology research to allow for individual identification. It has been shown to be less stressful than alternative marking methods and it is considered to be the most adequate and ethically sound method for durable marking of small lizards (Perry et al. 2011). I complied with reptile care guidelines and cut one toe per limb, which minimizes the effect on survival or locomotor performance for geckos (Paulissen and Meyer 2000; Hoehn et al. 2015). To prevent infection, I used a pair of sharp surgical scissors that were disinfected with ethanol and flame before and after cutting each toe. Many geckos marked with this technique were also recaptured throughout later field surveys. In all cases, the clipped areas had healed cleanly with no visible sign of infection or adverse effects on body condition.

\section{Results}

\section{Effects of developmental stage and individual body condition}

The developmental stage significantly affected the absolute value of exploration and boldness scores. Juveniles exhibited a significantly lower exploration score (the number of blocks per minute: median $\pm \mathrm{SD}=2.90 \pm 0.89$ times) than adults $(4.30 \pm 1.06$ times) $(\mathrm{LMM} ; t=-7.01, p<0.001)$. In boldness, juveniles were significantly bolder (hiding duration: median $\pm \mathrm{SD}=2.65 \pm 4.40 \mathrm{~min}$ ) than adults $(5.30 \pm 4.37 \mathrm{~min})(t=-2.27, p=0.026)$.

Individual body condition was related to exploration score, but there were significant differences between juveniles and adults (Table 1). SVL was positively correlated with exploration score in juveniles, but not in adults (Fig. 1). Adults with regenerated tails had higher exploration scores than those with original tails, but this tendency was not detected in juveniles. For boldness, no significant effect of individual body condition was detected in either developmental stage (Table 1). However, breaking the juveniles into two groups (small $\mathrm{SVL}<22 \mathrm{~mm}$; large $22 \mathrm{~mm}<\mathrm{SVL}<36.8 \mathrm{~mm}$ ), there was a relationship between SVL and boldness score. The small juvenile group was composed of only bolder individuals which showed short hiding duration $(<5 \mathrm{~min})$, whereas the large juvenile group and adults had more variation in their boldness (Fig. 1).

\section{Behavioural repeatability and syndrome structure}

In repeatability through the three consecutive tests, geckos in both developmental stages exhibited significant consistency in the two behavioural traits (Table 2). Exploration scores were repeatable in juveniles $($ ratio $=0.194)$ and adults (ratio $=0.277)$, and boldness scores were repeatable in juveniles $($ ratio $=0.436)$ and adults $($ ratio $=0.319)$. The random yearly factor significantly related to exploration in the juvenile stage, but not to boldness in either developmental stage.

When I examined test-retest repeatability, the mean boldness score was significantly correlated between the original test and the retest $\left(r_{s}=0.694, p=0.003, N=16\right)$. Mean exploration score of the original test was marginally correlated with the score of the retest $\left(r_{s}=0.481, p=0.059\right.$, $N=16)$. Finally, there was no significant correlation 
Table 1 Effect of individual body condition on exploration and boldness scores of mourning geckos

\begin{tabular}{llrrrr}
\hline Behavioural trait & Fixed factor & Estimate & SE & \multicolumn{1}{c}{$t$} \\
\hline Juvenile stage & & & & & \\
Exploration & Night of test & 0.04 & 0.08 & 0.57 & 0.569 \\
& Snout-vent length & 0.16 & 0.03 & 6.18 & $<\mathbf{0 . 0 0 1}$ \\
& Tail condition (regenerated) & 0.06 & 0.20 & 0.30 & 0.766 \\
Boldness & Night of test & -0.31 & 0.42 & -0.74 & 0.461 \\
& Snout-vent length & 0.29 & 0.20 & 1.48 & 0.147 \\
& Tail condition (regenerated) & 0.25 & 1.52 & 0.16 & 0.872 \\
Adult stage & & & & & \\
Exploration & Night of test & -0.13 & 0.10 & -1.30 & 0.197 \\
& Snout-vent length & 0.00 & 0.06 & 0.07 & 0.944 \\
& Tail condition (regenerated) & 0.71 & 0.29 & 2.43 & $\mathbf{0 . 0 2 0}$ \\
Boldness & Gravid condition (no eggs) & -0.12 & 0.30 & -0.39 & 0.698 \\
& Night of test & 0.89 & 0.49 & 1.81 & 0.074 \\
& Snout-vent length & -0.09 & 0.28 & -0.31 & 0.758 \\
& Tail condition (regenerated) & -0.91 & 1.40 & -0.65 & 0.520 \\
& Gravid condition (no eggs) & -2.27 & 1.45 & -1.56 & 0.127 \\
\hline
\end{tabular}

All estimates of fixed factors and statistics were derived from univariate linear mixed-effect models for each behavioural trait. Low boldness score indicates increased boldness, whilst high score indicates shyness. "Night of test" represents times that the experimental tests were conducted (1st, 2nd, and 3rd nights). Bold letters represent significant effect $(p<0.05)$
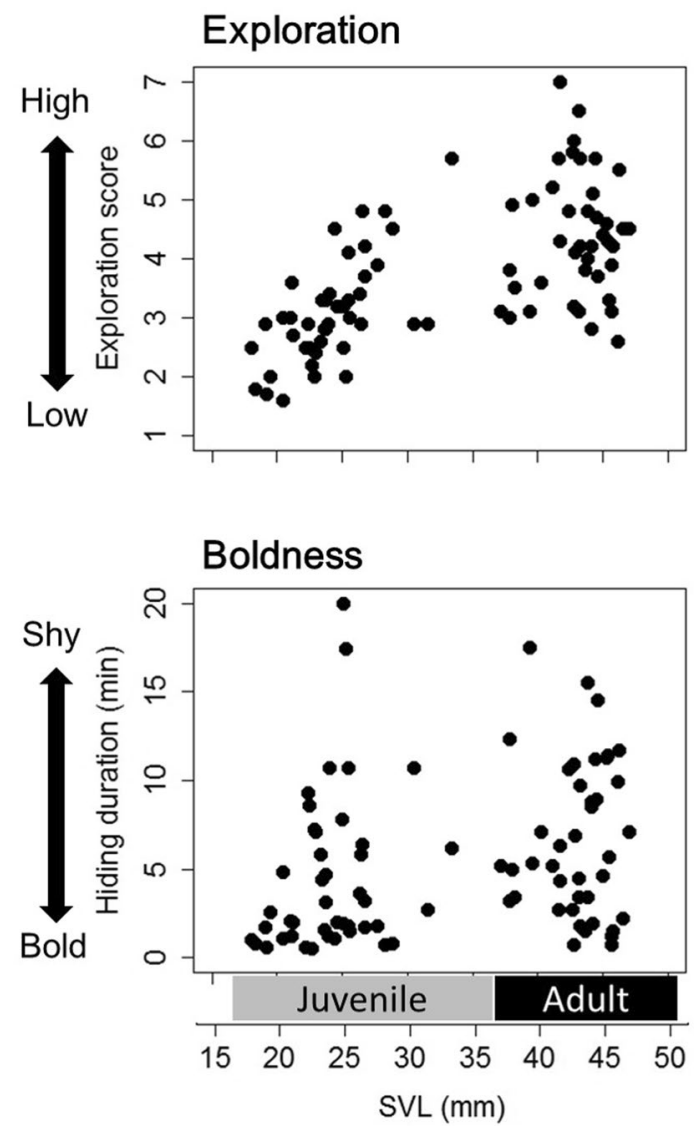

Fig. 1 Exploration and boldness scores of mourning geckos in relation to SVL. Each plot represents mean behavioural value of three tests for each gecko
Table 2 Variance and ratio of random factors on exploration and boldness scores of mourning geckos

\begin{tabular}{llrccc}
\hline $\begin{array}{l}\text { Behavioural } \\
\text { trait }\end{array}$ & Random factor & Variance & Ratio & LRT: $\chi^{2}$ & $P$ \\
\hline Juvenile stage & & & & & \\
Exploration & ID & 0.161 & 0.194 & 6.12 & $\mathbf{0 . 0 1 3}$ \\
& Year & 0.181 & 0.218 & 8.43 & $\mathbf{0 . 0 0 4}$ \\
& Residual & 0.488 & - & - & - \\
Boldness & ID & 13.315 & 0.436 & 22.98 & $<\mathbf{0 . 0 0 1}$ \\
& Year & 1.777 & 0.058 & 0.46 & 0.499 \\
& Residual & 15.450 & - & - & - \\
Adult stage & & & & & \\
Exploration & ID & 0.486 & 0.277 & 12.65 & $<\mathbf{0 . 0 0 1}$ \\
& Year & 0.269 & 0.153 & 1.49 & 0.222 \\
& Month & 0.174 & 0.099 & 0.00 & 1.000 \\
& Residual & 0.827 & - & - & - \\
Boldness & ID & 10.832 & 0.319 & 11.46 & $\mathbf{0 . 0 0 1}$ \\
& Year & 0.000 & 0.000 & 0.00 & 1.000 \\
& Month & 3.175 & 0.093 & 0.19 & 0.663 \\
& Residual & 19.998 & - & - & - \\
\hline
\end{tabular}

All estimates of random factors and statistics were derived from univariate linear mixed-effect models for each behavioural trait of each developmental stage. Repeatability is calculated as the ratio by dividing variance associated with ID effect by the total phenotypic variance (sum of variances). LRT represents $\chi^{2}$ statistics of log-likelihood ratio test, and bold letters represent significant effect $(p<0.05)$ 
between exploration and boldness scores in both juveniles $\left(r_{s}=-0.023, p=0.88, N=44\right)$ and adults $\left(r_{s}=-0.218\right.$, $p=0.17, N=41)$.

\section{Discussion}

In exploration and boldness scores, behavioural repeatability was detected in both juvenile and adult stages of mourning geckos, which shows that clonal geckos have personality traits. There was no behavioural correlation between exploration and boldness at either developmental stage. This indicates that juveniles and adults have similar personality structures and that exploration and boldness are independent from one another. This is the first study to report the presence of personality in parthenogenetic reptile species, although it is not the first to examine personality in genetically identical individuals. Previous studies have reported the presence of personality among genetically identical individuals in clonal pea aphids (Schuett et al. 2011, 2014), highly inbred mice (Lewejohann et al. 2011; Freund et al. 2013), and monozygotic human twins (Tellegen et al. 1988).

Most behavioural traits were not explained by individual body condition. The exception was tail condition in adults; geckos with regenerated tails were slightly more explorative than those with original tails (Table 1). Tail autotomy is an anti-predatory behaviour of lizards (Bateman and Fleming 2009). It is considered likely that geckos with regenerated tails have encountered predators in the past, thus a high explorative tendency may be associated with a high predation risk. From another perspective, it should be noted that learning or acclimation to the experiment could change a behavioural tendency because tests were conducted over three consecutive nights. However, the night of the test (1st, 2nd, or 3rd) did not significantly influence boldness or exploration scores in any case (Table 1). This suggests that the repeated measures did not induce a simple trend of learning or acclimation for geckos.

Smaller juveniles were mostly bold with low exploration scores whereas larger juveniles and adults had much more personality variation among individuals (Fig. 1). This biased composition of personality type on small juveniles could have caused the observed differences in boldness and exploration scores between developmental stages. Considering that the body size of juvenile reptiles is associated with age (Andrews 1982), it is likely that large juveniles were several months old and small juveniles were only days or weeks old when I tested them in September. Therefore, the appearance of shy and highly explorative individuals during this early ontogenetic stage may generate the personality variation of clonal geckos. This scenario raises the possibility that different environmental factors acting on each individual may form personalities along different trajectories.
At the group level, the exploration score of juveniles was lower than that of adults, which suggests that their exploration increases with age. The opposite trend has been reported in other vertebrates such as European green lizards, Lacerta viridis (Bajer et al. 2015) and red junglefowl, Gallus gallus (Favati et al. 2016). These highly explorative juveniles were generally explained by the energy demands needed for growth or migratory demands in order to avoid larger competitors. However, it should be noted that in the present experimental design, size dependent score bias cannot be eliminated because the exploration score was potentially influenced by relative body size to grid size of the arena. A stricter evaluation of exploration score based on relative body size is required for further discussion of exploration specific to developmental stage.

Juvenile geckos also tended to be bolder than adult geckos, suggesting that a risk taking tendency may decline with age. Similar tendencies have been reported in mustard leaf beetles, Phaedon cochleariae (Müller and Müller 2015), firebugs, Pyrrhocoris apterus (Gyuris et al. 2012), and red junglefowl (Favati et al. 2016). There are a number of explanations for why juveniles might be bolder than adults. First, the size specific predation risk of small juveniles might favour being bolder, which could increase growth. Boldness is positively linked to foraging activity (Mas-Muñoz et al. 2011) and high energy intake accelerates the growth rate of juvenile lizards (Andrews 1982). In small lizard species such as the mourning gecko, small invertebrates (e.g. spiders and centipedes) and other gecko species are potentially risky predators for juveniles (Bauer 1990; Bolger and Case 1992). Therefore, being bold might be a good strategy for juveniles to increase food intake and growth in order to be released from this specific predation pressure. Second, threat experiences may reduce the boldness level in geckos. Encounters with predators may make individuals learn to be shyer (Niemelä et al. 2012; Killen et al. 2013). Longer living individuals potentially have much more experience of encounters with predators than younger individuals, and such accumulated experiences may cause bold geckos to become shyer. Third, selective pressure may eliminate bolder individuals from the focal population. Correlation between survival rate and boldness is reported from various animals (Smith and Blumstein 2008). As a consequence of predation, risk-averse (shy) geckos may survive to an older age than risk-prone (bold) geckos. In order to investigate these possibilities relating to predators, manipulating tests are needed in a controlled environment, with and without predators.

In this study, I demonstrated that juvenile and adult clonal geckos have personality with similar structures. Differences of absolute values of boldness and exploration between developmental stages were detected, which may be due to biased individual composition of small juveniles. These 
results show that variation in personality increase during early ontogeny, potentially through the presence of a boldness/growth syndrome or through learning, which may help to understand personality forming throughout ontogeny. From this study, it is unclear whether personality type of individual geckos changes throughout their development, and if it does, what factors influence its change. Therefore, a longitudinal study is needed to clarify the developmental process of personality type within individuals throughout different life stages. It is also unclear whether the observed characteristics (e.g. small juvenile group was composed of only bold individuals) are specific to clonal animals or whether this is also normal in sexually reproducing taxa. I therefore advocate a comparative approach to studying the personality structure, variation, and absolute value of behavioural traits between clonal species and related sexual species in order to reveal the impact of genetic and environmental factors on the formation of personality.

Acknowledgements I am grateful to A. Mori for meaningful comments and discussion of my work, reviewing the manuscript, and providing accommodation near the field site. I would like to thank $\mathrm{C}$. Barnett for useful comments on this manuscript. I also appreciate the support and encouragement of the members of the Laboratory of Ethology, Kyoto University. The present study was carried out in compliance with the guidelines of the Animal Care and Use Committee of Kyoto University. The field survey was conducted with permission from the Department of Agriculture, Forestry and Fisheries of Okinawa Prefecture. I declare that I have no conflicts of interest.

\section{References}

Andrews RM (1982) Patterns of growth in reptiles. In: Gans C, Pough FH (eds) Biology of the Reptilia, vol 13. Academic Press, New York, pp 273-320

Bajer K, Horváth G, Molnár O, Török J, Garamszegi LZ, Herczeg G (2015) European green lizard (Lacerta viridis) personalities: linking behavioural types to ecologically relevant traits at different ontogenetic stages. Behav Processes 111:67-74. https://doi. org/10.1016/j.beproc.2014.11.020

Bateman PW, Fleming PA (2009) To cut a long tail short: a review of lizard caudal autotomy studies carried out over the last 20 years. J Zool 277:1-14. https://doi.org/10.1111/j.1469-7998.2008.00484.x

Bauer AM (1990) Gekkonid lizards as prey of invertebrates and predators of vertebrates. Herpetol Rev 21:83-87

Bell AM, Hankison SJ, Laskowski KL (2009) The repeatability of behaviour: a meta-analysis. Anim Behav 77:771-783. https://doi. org/10.1016/j.anbehav.2008.12.022

Bolger DT, Case TJ (1992) Intra- and interspecific interference behaviour among sexual and asexual geckos. Anim Behav 44:21-30. https://doi.org/10.1016/S0003-3472(05)80750-X

Carere C, Maestripieri D (eds) (2013) Animal personalities: behavior, physiology, and evolution. University of Chicago Press, Cicago

Carter AJ, Feeney WE, Marshall HH, Cowlishaw G, Heinsohn R (2013) Animal personality: What are behavioural ecologists measuring? Biol Rev 88:465-475. https://doi.org/10.1111/brv.12007

Class B, Brommer JE (2015) A strong genetic correlation underlying a behavioural syndrome disappears during development because of genotype-age interactions. Proc R Soc B 282:20142777. https ://doi.org/10.1098/rspb.2014.2777

Dingemanse NJ, Dochtermann NA (2013) Quantifying individual variation in behaviour: mixed-effect modelling approaches. J Anim Ecol 82:39-54. https://doi.org/10.1111/1365-2656.12013

Favati A, Zidar J, Thorpe H, Jensen P, Løvlie H (2016) The ontogeny of personality traits in the red junglefowl, Gallus gallus. Behav Ecol 27:484-493. https://doi.org/10.1093/beheco/arv177

Freund J, Brandmaier MA, Lewejohann L, Kirste I, Kritzler M, Krüger A, Sachser N, Lindenberger U, Kempermann G (2013) Emergence of individuality in genetically identical mice. Science 340:756759. https://doi.org/10.1126/science.1235294

Garamszegi LZ, Markó G, Herczeg G (2012) A meta-analysis of correlated behaviours with implications for behavioural syndromes: mean effect size, publication bias, phylogenetic effects and the role of mediator variables. Evol Ecol 26:1213-1235. https://doi. org/10.1007/s10682-012-9589-8

Gosling SD (2001) From mice to men: what can we learn about personality from animal research? Psychol Bull 127:45-86. https:// doi.org/10.1037/0033-2909.127.1.45

Groothuis TGG, Trillmich F (2011) Unfolding personalities: the importance of studying ontogeny. Dev Psychobiol 53:641-655. https:// doi.org/10.1002/dev.20574

Guenther A, Finkemeier M-A, Trillmich F (2014) The ontogeny of personality in the wild guinea pig. Anim Behav 90:131-139. https ://doi.org/10.1016/j.anbehav.2014.01.032

Gyuris E, Feró O, Barta Z (2012) Personality traits across ontogeny in firebugs, Pyrrhocoris apterus. Anim Behav 84:103-109. https:// doi.org/10.1016/j.anbehav.2012.04.014

Hoehn M, Henle K, Gruber B (2015) The effect of toe-clipping on the survival of gecko and skink species. Herpetol Conserv Biol 10:242-252. https://doi.org/10.3167/sa.2014.580207

Ineich I (1988) Evidence for a unisexual-bisexual complex in the gekkonid lizard Lepidodactylus lugubris in French Polynesia. Comptes Rendus de l'Academie des Sci Ser 3(307):271-277

Ineich I (1999) Spatio-temporal analysis of the unisexual-bisexual Lepidodactylus lugubris complex (Reptilia, Gekkonidae). In: Ota $\mathrm{H}$ (ed) Tropical island herpetofauna: origin, current diversity, and conservation. Elsevier, Amsterdam, pp 199-228

Ineich I, Ota H (1992) Additional remarks on the unisexual-bisexual complex of the gecko, Lepidodactylus lugubris, in Takapoto atoll, French Polynesia. Bull Coll Sci Univ Ryukyus 53:31-39

Kearney M, Fujita MK, Ridenour J (2009) Lost sex in the reptiles: constraints and correlations. In: Schön I, Martens K, Dijk P (eds) Lost sex: the evolutionary biology of parthenogenesis. Springer, Dordrecht, pp 447-474

Killen SS, Marras S, Metcalfe NB, McKenzie DJ, Domenici P (2013) Environmental stressors alter relationships between physiology and behaviour. Trends Ecol Evol 28:651-658. https://doi. org/10.1016/j.tree.2013.05.005

Kuznetsova A, Brockhoff PB, Christensen RHB (2015) lmerTest: tests in linear mixed effects models. R package version 2.0-25. http:// CRAN.R-project.org/package=lmerTest. Accessed 3 May 2015

Lewejohann L, Zipser B, Sachser N (2011) "Personality" in laboratory mice used for biomedical research: a way of understanding variability? Dev Psychobiol 53:624-630. https://doi.org/10.1002/ dev.20553

Mas-Muñoz J, Komen H, Schneider O, Visch SW, Schrama JW (2011) Feeding behaviour, swimming activity and boldness explain variation in feed intake and growth of sole (Solea solea) reared in captivity. PLoS One 6:e21393. https://doi.org/10.1371/journ al.pone.0021393

Moritz C, Case TJ, Bolger DT, Donnellan S (1993) Genetic diversity and the history of pacific island house geckos (Hemidactylus and Lepidodactylus). Biol J Linn Soc 48:113-133. https://doi. org/10.1111/j.1095-8312.1993.tb00882.x 
Müller T, Müller C (2015) Behavioural phenotypes over the lifetime of a holometabolous insect. Front Zool 12:S8. https://doi. org/10.1186/1742-9994-12-S1-S8

Murakami Y, Sugawara H, Takahashi H, Hayashi F (2015) Population genetic structure and distribution patterns of sexual and asexual gecko species in the Ogasawara Islands. Ecol Res 30:471-478. https://doi.org/10.1007/s11284-015-1246-6

Niemelä PT, DiRienzo N, Hedrick AV (2012) Predator-induced changes in the boldness of naïve field crickets, Gryllus integer, depends on behavioural type. Anim Behav 84:129-135. https:// doi.org/10.1016/j.anbehav.2012.04.019

Ota H (1994) Female reproductive cycles in the northernmost populations of the two gekkonid lizards, Hemidactylus frenatus and Lepidodactylus lugubris. Ecol Res 9:121-130. https://doi.org/10.1007/ BF02347487

Ota H, Toda M, Masunaga G, Toda M (2004) Feral populations of amphibians and reptiles in the Ryukyu archipelago, Japan. Glob Environ Res 8:133-143

Paulissen MA, Meyer HA (2000) The effect of toe-clipping on the gecko Hemidactylus turcicus. J Herpetol 34:282-285. https://doi. org/10.2307/1565425

Perry G, Wallace MC, Perry D, Curzer H, Muhlberger P (2011) Toe clipping of amphibians and reptiles: science, ethics, and the law. J Herpetol 45:547-555. https://doi.org/10.1670/11-037.1

Petelle MB, McCoy DE, Alejandro V, Martin JGA, Blumstein DT (2013) Development of boldness and docility in yellow-bellied marmots. Anim Behav 86:1147-1154. https://doi.org/10.1016/j. anbehav.2013.09.016

Radtkey RR, Donnellan SC, Fisher RN, Moritz C, Hanley KA, Case TJ (1995) When species collide: the origin and spread of an asexual species of gecko. Proc R Soc B 259:145-152. https://doi. org/10.1098/rspb.1995.0022

Réale D, Reader SM, Sol D, McDougall PT, Dingemanse NJ (2007) Integrating animal temperament within ecology and evolution. Biol Rev 82:291-318. https://doi.org/10.1111/j.1469185X.2007.00010.x

Sakai O (2016) Size distribution suggests a seasonal effect on reproduction of Lepidodactylus lugubris on Okinawajima Island, Japan, the northernmost distributional area. Curr Herpetol 35:59-63. https ://doi.org/10.5358/hsj.35.59

Schuett W, Dall SRX, Baeumer J, Kloesener MH, Nakagawa S, Beinlich F, Eggers T (2011) Personality variation in a clonal insect: the pea aphid, Acyrthosiphon pisum. Dev Psychobiol 53:631-640. https://doi.org/10.1002/dev.20538

Schuett W, Dall SRX, Kloesener MH, Baeumer J, Beinlich F, Eggers T (2014) Life-history trade-offs mediate "personality" variation in two colour morphs of the pea aphid, Acyrthosiphon pisum. J Anim Ecol 84:90-101. https://doi.org/10.1111/1365-2656.12263

Sih A, Bell AM, Jhonson JC, Ziemba RE (2004) Behavioral syndromes: an integrative overview. Q Rev Biol 79:241-277. https ://doi.org/10.1086/422893

Smith BR, Blumstein DT (2008) Fitness consequences of personality: a meta-analysis. Behav Ecol 19:448-455. https://doi.org/10.1093/ beheco/arm144

Stamps J, Groothuis TGG (2010) The development of animal personality: relevance, concepts and perspectives. Biol Rev 85:301-325. https://doi.org/10.1111/j.1469-185X.2009.00103.x

R Core Team (2013) R: a language and environment for statistical computing. Vienna (Austria): R foundation for statistical computing. http://www.R-project.org/

Tellegen A, Lykken DT, Bouchard TJ, Wilcox KJ, Segal NL, Rich S (1988) Personality similarity in twins reared apart and together. J Pers Soc Psychol 54:1031-1039

Vrijenhoek RC (1994) Unisexual fish: model systems for studying ecology and evolution. Annu Rev Ecol Syst 25:71-96

Wexler Y, Subach A, Pruitt JN, Scharf I (2016) Behavioral repeatability of flour beetles before and after metamorphosis and throughout aging. Behav Ecol Sociobiol 70:745-753. https://doi.org/10.1007/ s00265-016-2098-y

Wilmhoff CD, Csepeggi CE, Petren K (2003) Characterization of dinucleotide microsatellite markers in the parthenogenetic mourning gecko (Lepidodactylus lugubris). Mol Ecol Notes 3:400-402. https://doi.org/10.1046/j.1471-8286.2003.00459.x

Wilson DS, Clark AB, Coleman K, Dearstyne T (1994) Shyness and boldness in humans and other animals. Trends Ecol Evol 9:442446. https://doi.org/10.1016/0169-5347(94)90134-1

Wuerz Y, Krüger O (2015) Personality over ontogeny in zebra finches: long-term repeatable traits but unstable behavioural syndromes. Front Zool 12:S9. https://doi.org/10.1186/1742-9994-12-S1-S9

Yamashiro S, Toda M, Ota H (2000) Clonal composition of the parthenogenetic gecko, Lepidodactylus lugubris, at the northernmost extremity of its range. Zoolog Sci 17:1013-1020. https://doi. org/10.2108/zsj.17.1013 